\title{
A functional variant in HOXA11-AS, a novel long non-coding RNA, inhibits the oncogenic phenotype of epithelial ovarian cancer
}

\author{
Edward J. Richards ${ }^{1, *}$, Jennifer Permuth-Wey ${ }^{2, *}$, Yajuan Li $^{1, *}$, Y. Ann Chen ${ }^{3}$, \\ Domenico Coppola ${ }^{4}$, Brett M. Reid ${ }^{2}$, Hui-Yi Lin ${ }^{3}$, Jamie K. Teer ${ }^{3}$, Andrew Berchuck ${ }^{5}$, \\ Michael J. Birrer ${ }^{6}$, Kate Lawrenson ${ }^{7}$, Alvaro N.A. Monteiro' ${ }^{2}$, Joellen M. Schildkraut ${ }^{8}$, \\ Ellen L. Goode ${ }^{9}$, Simon A. Gayther ${ }^{7}$, Thomas A. Sellers ${ }^{2}$ and Jin Q. Cheng ${ }^{1}$ \\ ${ }^{1}$ Department of Molecular Oncology, Moffitt Cancer Center, Tampa, FL, USA \\ 2 Department of Cancer Epidemiology, Moffitt Cancer Center, Tampa, FL, USA \\ ${ }^{3}$ Department of Biostatistics and Bioinformatics, Moffitt Cancer Center, Tampa, FL, USA \\ ${ }^{4}$ Department of Anatomic Pathology, Moffitt Cancer Center, Tampa, FL, USA \\ ${ }^{5}$ Department of Obstetrics and Gynecology, Duke University Medical Center, Durham, North Carolina, USA \\ ${ }^{6}$ Massachusetts General Hospital, Boston, MA, USA \\ 7 Department of Preventive Medicine, Keck School of Medicine, University of Southern California, Norris Comprehensive \\ Cancer Center, Los Angeles, California, USA \\ ${ }^{8}$ School of Medicine, Public Health Sciences, University of Virginia, Charlottesville, VA, USA \\ ${ }^{9}$ Department of Health Science Research, Division of Epidemiology, Mayo Clinic, Rochester, MN, USA \\ * These authors have contributed equally to this manuscript \\ Correspondence to: Jin Q. Cheng, email: jin.cheng@moffitt.org
}

Thomas A. Sellers, email: Thomas.sellers@moffitt.org

Keywords: ovarian cancer, genetic susceptibility, HOX cluster, long non-coding RNAs, single nucleotide polymorphisms Received: June 14, $2015 \quad$ Accepted: August 31, 2015

Published: September 22, 2015

This is an open-access article distributed under the terms of the Creative Commons Attribution License, which permits unrestricted use, distribution, and reproduction in any medium, provided the original author and source are credited.

\section{ABSTRACT}

The homeobox A (HOXA) region of protein-coding genes impacts female reproductive system embryogenesis and ovarian carcinogenesis. The 5-prime end of HOXA includes three long non-coding RNAs (IncRNAs) (HOXA10-AS, HOXA11-AS, and HOTTIP) that are underexplored in epithelial ovarian cancer (EOC). We evaluated whether common genetic variants in these IncRNAs are associated with EOC risk and/or have functional roles in EOC development. Using genome-wide association study data from 1,201 serous EOC cases and 2,009 controls, an exonic variant within HOXA11-AS, rs17427875 (A $>$ T), was marginally associated with reduced serous EOC risk $(\mathrm{OR}=0.88(95 \% \mathrm{CI}: 0.78-1.01, p=0.06)$. Functional studies of ectopic expression of HOXA11-AS minor allele $\mathrm{T}$ in EOC cells showed decreased survival, proliferation, migration, and invasion compared to common allele A expression. Additionally, stable expression of HOXA11-AS minor allele $T$ reduced primary tumor growth in mouse xenograft models to a greater extent than common allele A. Furthermore, HOXA11-AS expression levels were significantly lower in human EOC tumors than normal ovarian tissues $(p<0.05)$, suggesting that HOXA11-AS has a tumor suppressor function in EOC which may be enhanced by the $T$ allele. These findings demonstrate for the first time a role for HOXA11-AS in EOC with effects that could be modified by germline variants. 


\section{INTRODUCTION}

The homeobox (HOX) family of genes are transcription factors that contribute to embryogenesis and carcinogenesis [1]. They are characterized by highly conserved homeodomains which enable HOX proteins to bind to specific DNA regions and activate or repress transcription of their target genes [2]. In the human genome, $H O X$ genes are organized into four clusters (A, B, C, and D) located on four different chromosomes [3]. During the development of the female reproductive system, several ' $H O X A$ ' cluster genes that map to $7 \mathrm{p} 15.2$ (HOXA9, HOXA10, HOXA11, and HOXA13) are expressed uniformly along the Müllerian duct axis, though in adults their expression is confined to specific female organs $[2,4]$. Since $H O X A$ genes promote aberrant epithelial differentiation [4], their expression has been evaluated in epithelial ovarian cancer (EOC), a malignancy that accounts for more deaths in North America than any other cancer of the female reproductive system [5]. Increased expression of several HOXA genes has been reported in human EOCs compared to normal ovarian surface epithelial (OSE) precursor tissues [4, 6-9]. The HOXA gene cluster is organized into a sense strand containing protein-coding genes and an antisense strand containing non-coding RNA (ncRNA) genes (Supplemental Figure 1A). The 5-prime region of the HOXA locus refers to the direction of the sense strand with respect to protein coding genes, with $H O X A 13$ being the most 5-prime protein-coding gene (Supplemental Figure 1B). The 5 -prime region includes three additional protein-coding genes (HOXA11, HOXA10, and HOXA9) and 3 lncRNAs, HOTTIP, HOXA11-AS, and HOXA10-AS. While several investigations support a role for the HOXA cluster of protein-coding genes $[2,4]$ in ovarian embryogenesis and carcinogenesis, less is known regarding the locally residing lncRNAs and how they may contribute to these processes [10]. Based on recent reports which suggest that lncRNAs in the 5-prime distal region have a functional role in promoting malignant phenotypes [11-13], a rationale exists for their investigation in EOC.

Common germline genetic variants, or single nucleotide polymorphisms (SNPs), affecting lncRNAs have been shown to contribute to the development of multiple cancer types [14-19]. The objective of this investigation was to comprehensively examine inherited genetic variation in the three lncRNAs in the 5 ' end of the HOXA cluster region (HOXA10-AS, HOXA11-AS, and HOTTIP) in EOC. In particular, we tested the hypotheses that these variants associated with EOC risk, in vitro cell survival or proliferation, in vitro migration or invasion, EOC growth in vivo, and tumor expression. To examine risk, we evaluated genotype and clinical data from 1,201 invasive serous EOC cases and 2,009 controls from a North American genome-wide association study (GWAS) of EOC (Table 1). To evaluate functional aspects, we tested the most promising candidate SNP for functional impact using in vitro and in vivo assays. Our results suggest that although germline variants in lncRNA sequences within the HOXA cluster are not convincingly associated with EOC risk, these variants could be functional in driving malignant phenotypes associated with cancer. This line of research provides a new opportunity to advance our understanding of HOXA cluster-mediated regulation of EOC development.

\section{RESULTS}

\section{Association of InRNA SNPs in the HOXA cluster with EOC risk}

We evaluated associations between 21 individual variants in 3 unique lncRNAs in the HOXA cluster region and serous EOC susceptibility using data from our GWAS. Figure 1 presents the regional association plot for the SNP-level p-values for the 21 variants, and for reference, 669 variants mapping to the $150 \mathrm{~kb}$ flanking regions. No SNPs within the 3 lncRNAs were associated with serous EOC risk at a significance threshold of $p<0.05$ (Table 2). Only HOXA11-AS SNP rs17427875 (A > T; minor allele frequency $(\mathrm{MAF})=0.20$ ) was marginally associated with a reduced risk for serous EOC $(\mathrm{OR}(95 \% \mathrm{CI})=0.88(0.78$ $1.01), p=0.060$ ) (Table 2; Figure 1). SNP rs17427875 is not in linkage disequilibrium $\left(\mathrm{r}^{2}<0.01\right)$ with $\mathrm{rs} 11564004$, the top-ranked SNP in the $150 \mathrm{~kb}$ region downstream of the HOXA cluster $(\mathrm{OR}(95 \% \mathrm{CI})=0.78(0.63-0.96), p$ $=0.02$ ) (Figure 1A). Per the UCSC Genome Browser, rs 17427875 is highly conserved across 100 vertebrates (majority species have only A allele), and is in a conserved peak. It also falls within an H3K27 ChIP region, a DNaseI hypersensitivity cluster, and several transcription factor ChIP regions including EZH2 and POLR2A (Figure 1B).

\section{$H O X A 11-A S$ rs17427875 minor allele inhibits cell survival and proliferation more significantly than common allele}

HOXA11-AS is a highly conserved lncRNA across several species (Figure 1B) [20], suggesting that this gene was retained through selective evolutionary pressures. Since the top-ranked candidate lncRNA SNP rs17427875 $(\mathrm{A}>\mathrm{T})$ resides within a likely regulatory region within the first exon we tested for allele-specific effects on the cellular phenotypes of in vitro models of EOC (Figure 2). We cloned the full-length $H O X A 11-A S$ common allele construct, and then performed site-directed mutagenesis to generate a plasmid expressing the minor allele. We then transfected OVCA-433 and C13 ovarian cancer cell lines with either the full-length $H O X A 11-A S$ common allele 
Table 1: Characteristics of participating genome-wide association studies of epithelial ovarian cancer

\begin{tabular}{|c|c|c|c|c|c|c|}
\hline \multirow{2}{*}{ Study Name } & \multirow{2}{*}{ Study Population } & \multirow{2}{*}{$\begin{array}{l}\text { Genotyping } \\
\text { Platform }\end{array}$} & \multirow{2}{*}{ Study Type } & \multicolumn{3}{|c|}{ Number of subjects $^{1}$} \\
\hline & & & & cases & serous & controls \\
\hline \multicolumn{7}{|c|}{ North America } \\
\hline Mayo Clinic Ovarian Cancer Study & Upper Midwest, USA & Illumina $610 \mathrm{~K}$ & Clinic based & 359 & 237 & 520 \\
\hline North Carolina Ovarian Cancer Study & North Carolina, USA & Illumina $610 \mathrm{~K}$ & Population based & 494 & 285 & 654 \\
\hline Tampa Bay Ovarian Cancer Study & Tampa, USA & Illumina $610 \mathrm{~K}$ & Population based & 227 & 146 & 169 \\
\hline Familial Ovarian Tumor Study & Ontario, Canada & Illumina $610 \mathrm{~K}$ & Population based & 734 & 401 & 524 \\
\hline New England Case-Control Study of Ovarian Cancer & New England, USA & $\begin{array}{c}\text { Illumina } 317 \mathrm{~K}, \\
370 \mathrm{~K}\end{array}$ & Population based & $133^{2}$ & 132 & 142 \\
\hline Total & & & & 1,947 & 1,201 & 2,009 \\
\hline
\end{tabular}

${ }^{1}$ Totals represent the number of non-Hispanic white Europeans passing genotyping quality control criteria and meeting study site-specific inclusion/exclusion criteria with data available on disease status, age at diagnosis/interview, self-reported racial group, and histologic subtype.

${ }^{2}$ Cases from NEC that were evaluated as part of this investigation represent postmenopausal advanced papillary serous carcinomas; 26 of these cases were ascertained as part of a hospital-based pre-operative study.

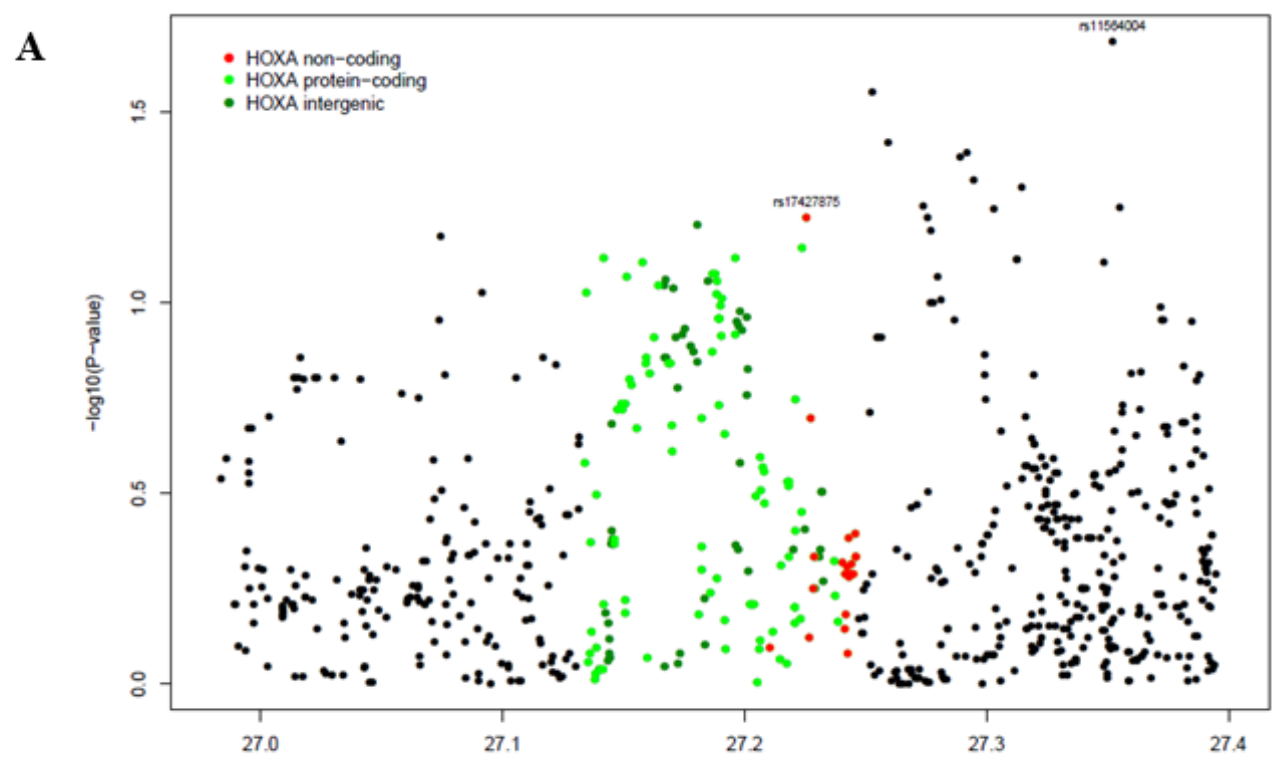

B

Chromosome 7 position (Mb)

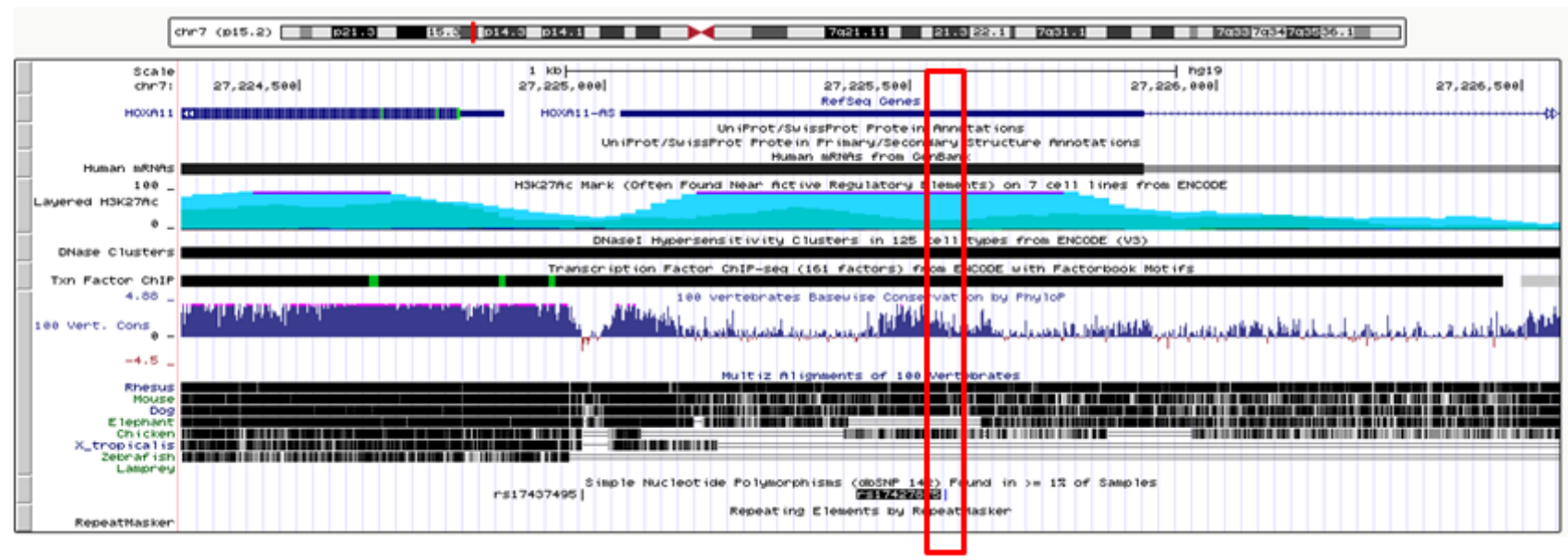

Figure 1: The associations of HOXA IncRNA SNP genotypes and surrounding SNPs with epithelial ovarian cancer risk. A. Regional association plot showing results of association testing between the genotypes of 21 SNPs residing in the 3 HOXA IncRNAs (designated by red dots) and the risk of serous EOC (1201 cases, 2009 controls). Also shown are results of association testing for SNPs residing within HOXA protein-coding genes (green dots), SNPs falling in intergenic regions (blue dots), and SNPs residing outside the HOXA cluster (black dots). rs17427875, which falls within HOXA11-AS, is the top-ranking lncRNA SNP in the region. B. Genome browser shot of HOXA11, HOXA11-AS and the location of the rs17427875, which sits within an evolutionarily conserved region. 
Table 2: Polymorphisms associated with the risk of invasive serous epithelial ovarian cancer

\begin{tabular}{|c|c|c|c|c|c|c|c|c|c|c|}
\hline \multirow[b]{2}{*}{ Gene } & \multirow[b]{2}{*}{ Locus } & \multirow[b]{2}{*}{ SNP $^{1}$} & \multirow[b]{2}{*}{ A1 } & \multirow[b]{2}{*}{ A2 } & \multirow[b]{2}{*}{ MAF } & \multicolumn{4}{|c|}{ (1,201 cases; 2,009 controls) } & \multirow[b]{2}{*}{ FDR } \\
\hline & & & & & & OR & LL_Cl & UL_Cl & $\mathbf{P}$ & \\
\hline HOTTIP & $7 p 15.2$ & rs $3735533^{a}$ & $\mathrm{C}$ & $\mathrm{T}$ & 0.08 & 0.92 & 0.76 & 1.12 & 0.405 & 0.078 \\
\hline HOTTIP & $7 p 15.2$ & rs $10233387^{b}$ & G & $A$ & 0.45 & 1.04 & 0.94 & 1.15 & 0.414 & 0.070 \\
\hline HOTTIP & $7 p 15.2$ & $\operatorname{chr} 7: 27245992^{a}$ & G & $G G$, & 0.08 & 0.93 & 0.77 & 1.13 & 0.463 & 0.078 \\
\hline HOTTIP & $7 p 15.2$ & $\operatorname{chr} 7: 27245995^{a}$ & $\mathrm{G}$ & $\mathrm{GC}$ & 0.08 & 0.93 & 0.77 & 1.13 & 0.463 & 0.078 \\
\hline HOTTIP & $7 p 15.2$ & rs $3807598^{b}$ & $\mathrm{C}$ & G & 0.46 & 1.04 & 0.94 & 1.15 & 0.480 & 0.070 \\
\hline HOTTIP & $7 p 15.2$ & $\operatorname{chr} 7: 27244306^{a}$ & TT & & 0.08 & 0.93 & 0.77 & 1.13 & 0.486 & 0.076 \\
\hline HOTTIP & $7 p 15.2$ & rs1859168 ${ }^{a}$ & C & $A$ & 0.08 & 0.94 & 0.77 & 1.13 & 0.494 & 0.070 \\
\hline HOTTIP & $7 p 15.2$ & rs2023844 ${ }^{a}$ & $A$ & G & 0.08 & 0.94 & 0.78 & 1.14 & 0.516 & 0.070 \\
\hline HOTTIP & $7 p 15.2$ & $\mathrm{rs} 4722675^{\mathrm{a}}$ & $\mathrm{G}$ & $A$ & 0.08 & 0.94 & 0.78 & 1.14 & 0.516 & 0.070 \\
\hline HOTTIP & $7 p 15.2$ & rs929250 ${ }^{a}$ & $\mathrm{~T}$ & $G$ & 0.08 & 0.94 & 0.78 & 1.14 & 0.516 & 0.078 \\
\hline HOTTIP & $7 p 15.2$ & rs2067087 & $\mathrm{C}$ & G & 0.28 & 0.96 & 0.86 & 1.08 & 0.516 & 0.070 \\
\hline HOTTIP & $7 p 15.2$ & $r s 2023843^{a}$ & $\mathrm{~T}$ & C & 0.08 & 0.94 & 0.78 & 1.14 & 0.527 & 0.070 \\
\hline HOTTIP & $7 p 15.2$ & $\operatorname{chr} 7: 27241878^{c}$ & $A$ & $\mathrm{ACl}$ & 0.1 & 1.04 & 0.88 & 1.23 & 0.655 & 0.070 \\
\hline HOTTIP & $7 p 15.2$ & rs17501292 & $\mathrm{T}$ & G & 0.18 & 0.98 & 0.86 & 1.11 & 0.720 & 0.070 \\
\hline HOTTIP & $7 p 15.2$ & rs2240042 ${ }^{c}$ & $\mathrm{C}$ & $\mathrm{T}$ & 0.1 & 1.02 & 0.86 & 1.21 & 0.832 & 0.070 \\
\hline HOXA10-AS & $7 p 15.2$ & chr7:27210428 & A & $A G$ & 0.44 & 0.99 & 0.89 & 1.09 & 0.801 & 0.070 \\
\hline HOXA11-AS & $7 p 15.2$ & rs17427875 & A & $\mathrm{T}$ & 0.2 & 0.88 & 0.78 & 1.01 & 0.060 & 0.070 \\
\hline HOXA11-AS & $7 p 15.2$ & rs2285724 & $A$ & G & 0.4 & 0.94 & 0.85 & 1.04 & 0.201 & 0.070 \\
\hline HOXA11-AS & $7 p 15.2$ & $\operatorname{chr} 7: 27228665^{c}$ & $G$ & $\mathrm{GCl}$ & 0.1 & 1.07 & 0.90 & 1.26 & 0.464 & 0.070 \\
\hline HOXA11-AS & $7 p 15.2$ & rs79658629 & $\mathrm{G}$ & A & 0.1 & 1.05 & 0.88 & 1.26 & 0.563 & 0.070 \\
\hline HOXA11-AS & $7 p 15.2$ & rs4722669 & $\mathrm{C}$ & $\mathrm{T}$ & 0.08 & 1.03 & 0.86 & 1.24 & 0.759 & 0.070 \\
\hline
\end{tabular}

\begin{tabular}{l}
\hline Based on human genome build 37 ; dbSNP 141 \\
\hline Abbreviations: $A 1=$ common allele; $A 2=$ minor allele; MAF=minor allele frequency \\
OR=odds ratio, adjusted for study site and the first principal component representing \\
European ancestry; $L L \_C l=l o w e r$ limit of the $95 \%$ confidence interval; UL_Cl=upper limit of the \\
95\% confidence interval \\
a,b,c: Denote SNP blocks with $r 2>0.8$
\end{tabular}

or the full-length minor allele constructs and assessed phenotypic changes. Forty-eight hours after transfection we observed by real-time PCR that both common and minor allele expression was similar, at $\sim 169$ and 171fold over-expression in OVCA-433, respectively, when compared to vector control (Figure 2A). In both common and minor allele constructs, ectopic expression of the $H O X A 11-A S$ resulted in a significant reduction of cell survival and proliferation, two major cellular processes associated with EOC development (Figures 2B-2C). Notably, the minor allele resulted in significantly less survival and proliferation compared to the common allele $(p=0.0022$ and $p=0.021)$. Similar findings were observed in C13 cells (Figure 2D).

\section{The effects of HOXA11- $A S$ rs17427875 on EOC migration and invasion}

Epithelial-mesenchymal transition (EMT), migration, and invasion are important cellular phenotypes that are associated with early EOC development, progression and metastasis [21]. We therefore investigated if $H O X A 11-A S$ SNP rs 17427875 regulates cell migration and invasion. Following transfection of minor allele and common allele constructs of HOXA11-AS for 48 hours, OVCA-433 and C13 cells were subjected to a twochamber assay. In OVCA-433, expression of both common allele and minor allele reduced cell migration $(p=0.029$ and 0.0023 , respectively) and invasion $(p=0.0082$ and 0.0004 , respectively). However, the minor allele exhibited a more significant inhibitory effect in both assays than the common allele ( $p=0.019$ and 0.0043 , respectively) (Figure 3A-3B). Similar results were obtained in $\mathrm{C} 13$ cells (Figure 3C-3D).

Collectively, these findings suggest that the minor allele functions to inhibit oncogenic phenotypes to a more significant extent than the common allele in EOC cells. This is consistent with the epidemiologic trend towards reduced EOC risk among women carrying the HOXA11$A S$ rs 17427875 T allele $(\mathrm{OR}=0.88, p=0.060)$.

\section{HOXA11-AS rs17427875 SNP inhibits EOC growth in vivo}

Having demonstrated HOXA11-AS rs17427875 SNP function in cell culture, we next investigated the 
effect of this SNP on EOC tumorigenicity in a xenograft model. C13 cells were transfected with vector, common allele, and minor allele constructs. After G418 selection, stably transfected cells were subcutaneously injected into nude mice ( $4 \times 10^{6} /$ mouse, 8 mice/group). Tumors were engrafted and allowed to grow for 8 weeks at which point the vector control group reached tumor burden endpoint. We observed a reduced tumor size and weight in common allele and minor allele treated mice as compared to the vector control group. Notably, tumor size and weight were significantly less in the minor allele group as compared to the common allele group (Figure 4A and 4B). Furthermore, histological analysis and immunostaining of tumor sections revealed that expression of the minor allele $\mathrm{T}$ reduced mitosis and significantly induced apoptosis when compared to vector control $(p=0.003)$ and common allele ( $p=0.02$, Figure 4C-4D). In contrast, there was no effect of the minor allele on angiogenesis (data not shown). This denotes that the HOXA11-AS SNP functions to inhibit tumor growth more significantly than the common allele in vivo.

\section{HOXA11- $A S$ expression in EOC}

In addition, we evaluated $H O X A 11-A S$ expression and the effect of rs17427875 on HOXA11-AS levels in 18 human EOC tumor-normal pairs using semi-quantitative PCR. Using densitometry analysis, expression of HOXA11-AS was decreased on average more than $60 \%$ in EOC tumor tissue versus normal ovarian tissue ( $p=$ 6.5×10-3; Figure 5A and 5B). The decreased HOXA11-AS expression was independent of genotype (Supplemental Figure 2). Taken together, these findings suggest a tumor suppressor role for $H O X A 11-A S$ in EOC and minor allele T having no effect on $H O X A 11-A S$ expression.

\section{Ectopic expression and knockdown of $\mathrm{HOXA11-}$ $A S$ has no effect on HOXA11 and HOXA13 expression in EOC}

We also investigated the mechanism by which $H O X A 11-A S$ inhibits oncogenic phenotypes in EOC. The

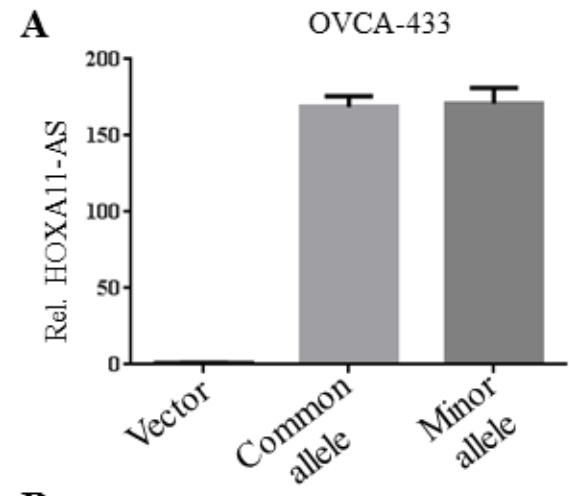

B

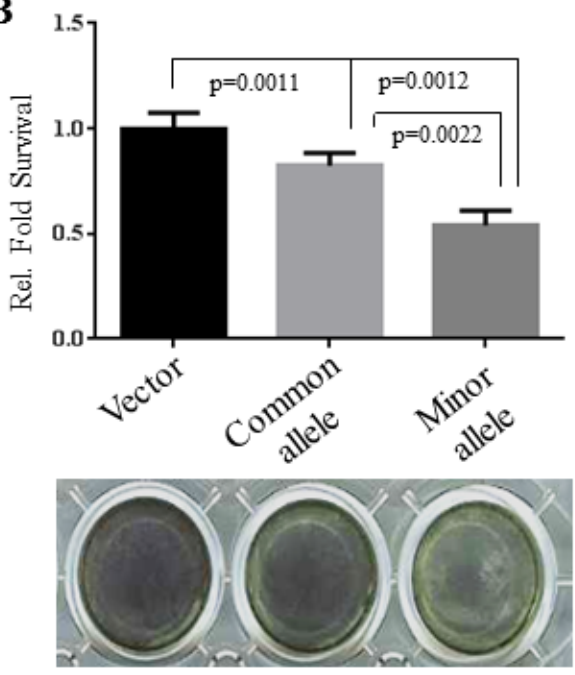

C

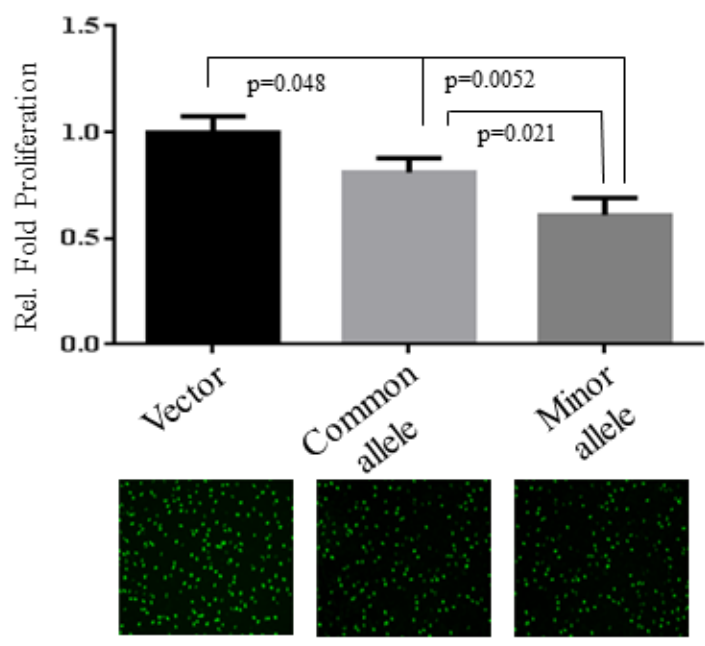

D

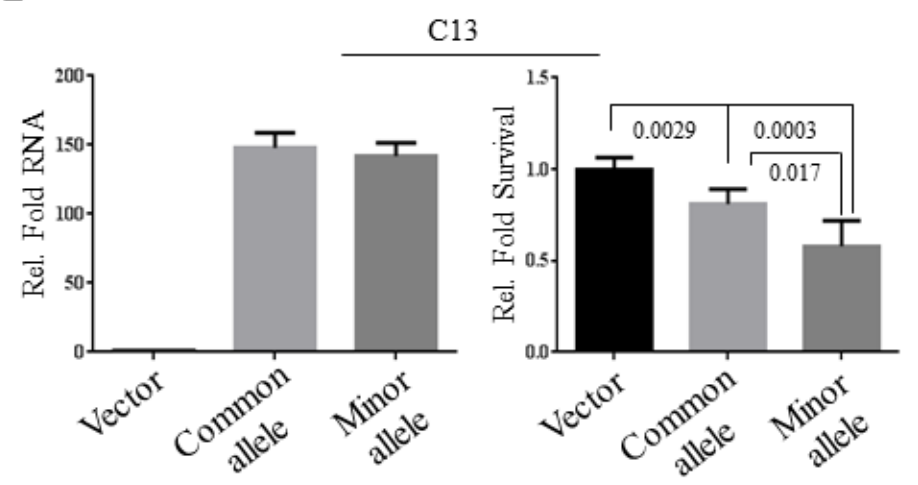

Figure 2: Ectopic expression of the rs17427875 (A > T) variant allele $(\mathrm{T})$ inhibits survival and proliferation. A. OVCA433 cells were transfected with vector, common allele, and minor allele of HOXA11-AS. Expression of transfected constructs was measured by real-time qPCR. B. The transfected cells were subjected to MTT assay for cell viability. C. Edu incorporation for DNA synthesis/cell proliferation. D. C13 cells were transfected and evaluated for cell survival as described in panels A and B. The survival and growth of vector-transfected cells were normalized to 1.0. Statistical significance was determined using unpaired Student's $t$ test. 
HOXA11-AS is a natural antisense transcript, which is also called antisense lncRNA, located at the 5' region but not overlapping with the protein coding gene HOXA11 (Supplemental Figure 1). Previous studies have shown that a number of antisense lncRNAs regulate their neighboring genes through a cis mechanism [22]. Thus, we assessed HOXA11 protein and mRNA levels following enforced expression and knockdown of $H O X A 11-A S$ in EOC cell lines. Transfection of common and minor alleles of HOXA11-AS into A2780CP and C13 cells had no effects on HOXA11 expression at both protein (Figure 6A) and mRNA (Figure 6C) levels. Furthermore, expression of HOXA11 was not changed after knockdown of HOXA11$A S$ in $\mathrm{C} 13$ and OV2008 as well as A2780CP cells (Figure 6B-6C). Since HOXA13 is also close to HOXA11-AS in

A

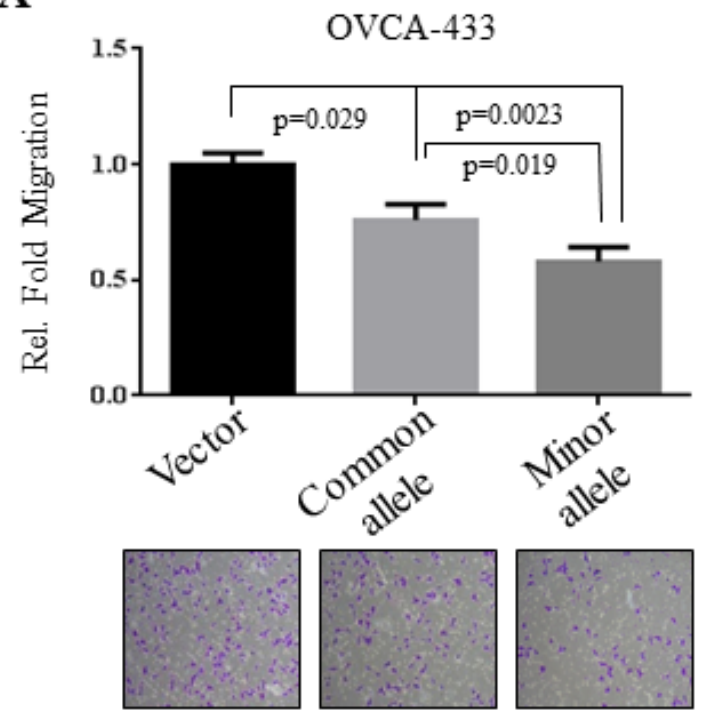

C

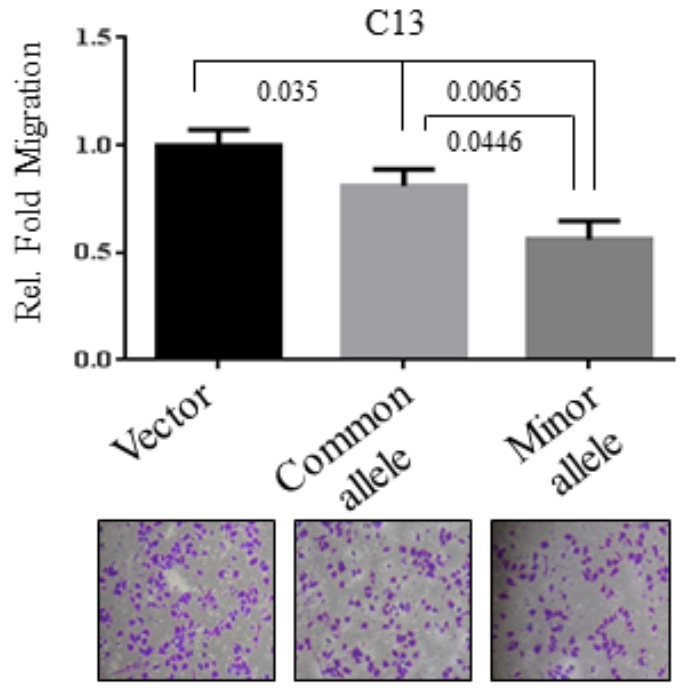

an opposite orientation (Supplemental Figure 1), we next examined if HOXA11- $A S$ regulates HOXA13. RT-qPCR analysis revealed no significant changes of $H O X A 13$ mRNA level after expression or knockdown of $H O X A 11$ $A S$ (Figure 6D). These findings suggest that HOXA11- $A S$ does not regulate $H O X A 11$ and HOXA13.

\section{DISCUSSION}

Dysregulation of the $H O X$ cluster of genes has been shown in many human diseases, including EOC $[1,2,23]$. The current study represents the first investigation to focus on the association between genetic variants involving lncRNAs in the HOXA gene cluster region and EOC risk and development. Our GWAS identified rs17427875,

B

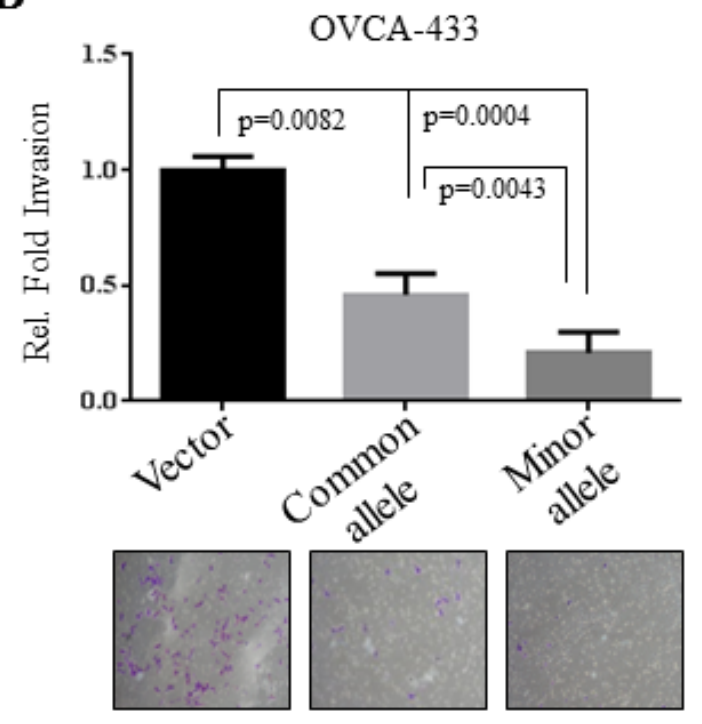

D

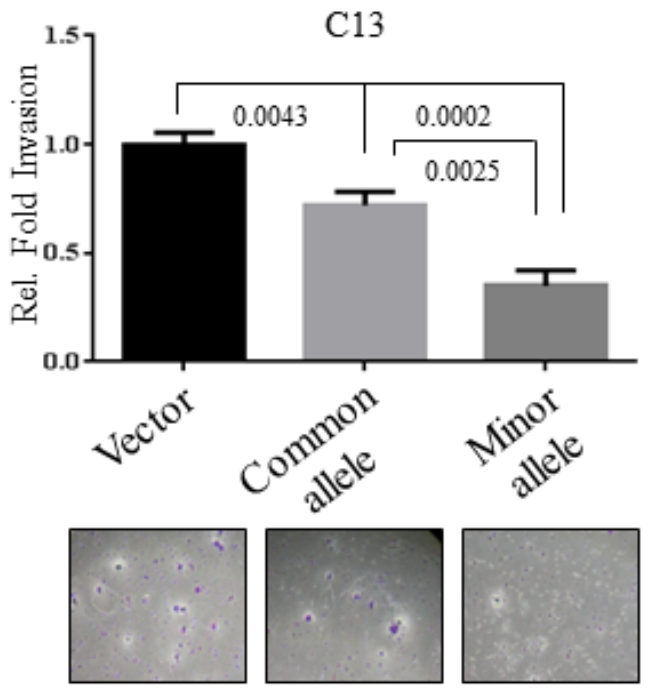

Figure 3: Inhibitory effects of rs17427875 (A > T) on EOC migration and invasion. OVCA-433 and C13 cells were transfected with indicated constructs and then assayed for cell A. and C. migration and B. and D. invasion using Boyden chamber assays. Data analysis was performed as described in Figure 2. 
A
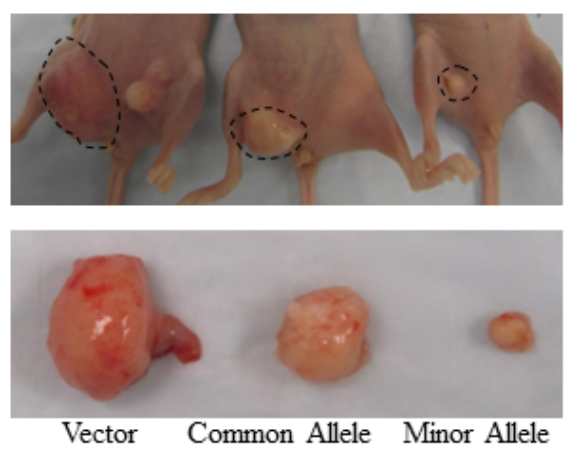

\begin{tabular}{|c|c|c|}
\hline $\begin{array}{c}\text { Groups } \\
(\mathrm{n}=8 / \text { group })\end{array}$ & $\begin{array}{c}\text { Ave. tumor } \\
\text { volume } \\
\left(\mathbf{m m}^{3}\right)\end{array}$ & $\begin{array}{c}\text { Ave. tumor } \\
\text { weight } \\
(\mathbf{m g})\end{array}$ \\
\hline Vector & 1281.5 & 2608 \\
\hline Common Allele & $482.2 \dagger$ & $502 \dagger$ \\
\hline $\begin{array}{c}\text { Minor } \\
\text { Allele }\end{array}$ & $102.6 \dagger$ & $108 \dagger$ \\
\hline
\end{tabular}

$\dagger \mathrm{p}<0.05$

C

Vector

$112 / 10 \mathrm{hpf}$

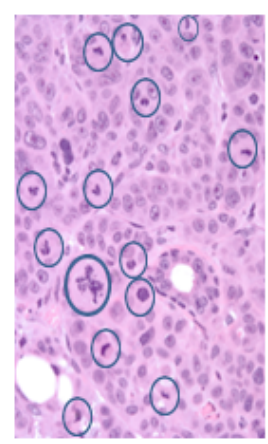

Common Allele $104 / 10 \mathrm{hpf}$

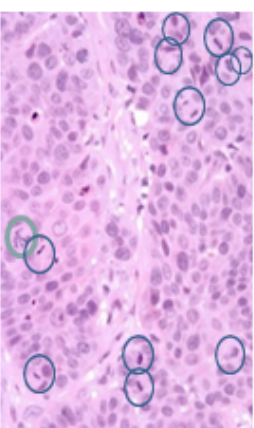

Minor Allele $27 / 100 \mathrm{hpf}$

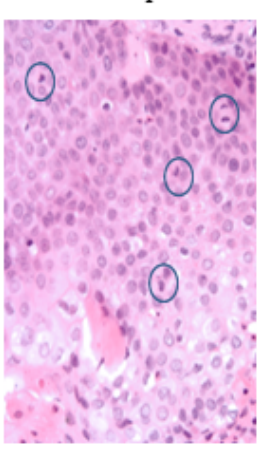

D

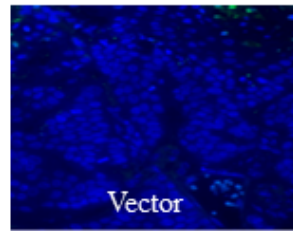

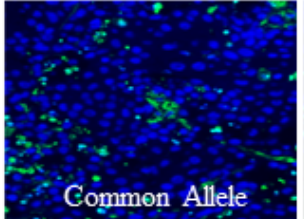
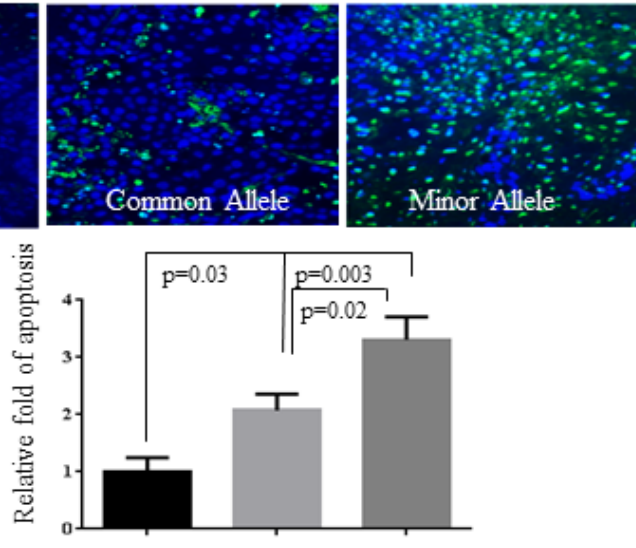

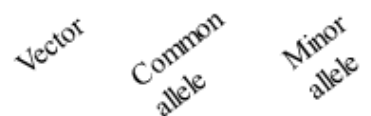

Figure 4: HOXA11-AS inhibits EOC tumor growth in xenograft model. A. C13 cells were stably transfected with vector, common allele, and minor allele constructs. The stable transfected cells were subcutaneously injected to nude mice $\left(4 \times 10^{6}\right.$ cells $/$ mouse, 8 mice/group) and the image was taken at the 8-week endpoint. B. Tumor volume was calculated using standard caliper measurements and tumor weight was measured and quantified. C. Histological analysis of H\&E staining tumor section. The number of mitotic cells was expressed as mitoses per 10 high-power (x40) microscopic fields. D. Tunel assays were performed in xenograft tumor sections. Apoptotic cells were quantified.

A

\section{Normal Ovary}

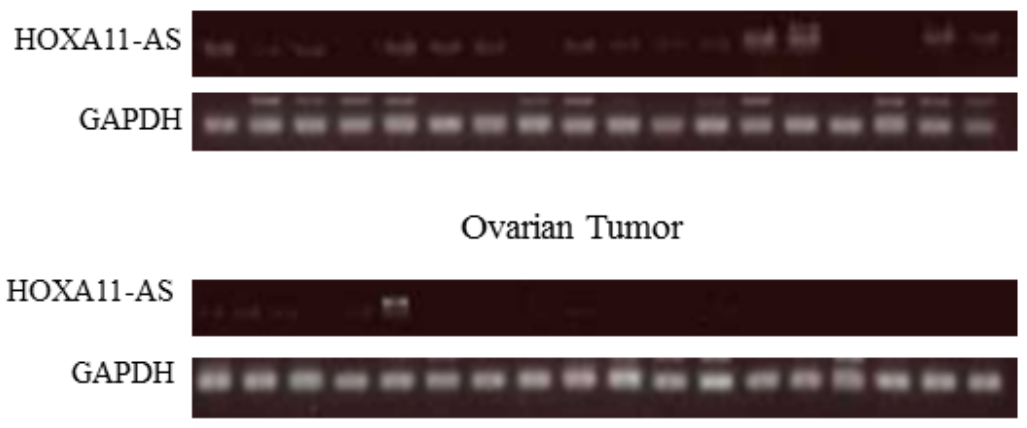

B

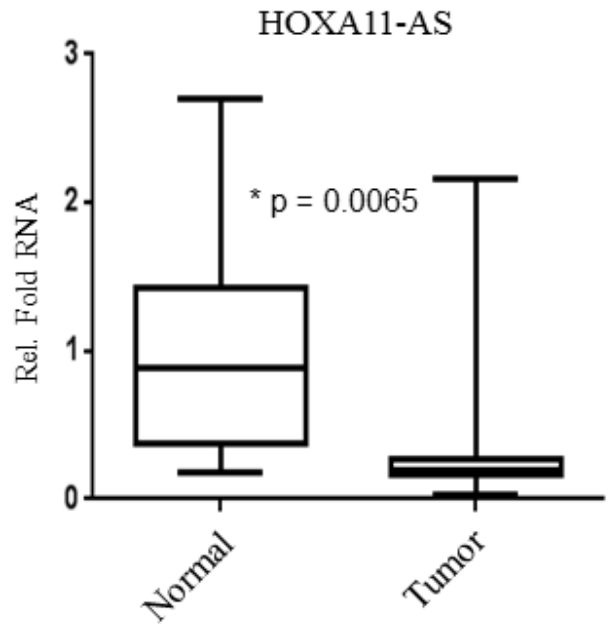

Figure 5: $\mathrm{HOX} A 11-A S$ expression is down-regulated in human EOC tumor. A. Semi-quantitative RT-PCR analysis of HOXA11-AS expression in human EOC tumors and matched normal ovarian tissues. B. Quantification and statistical analysis of HOXA11$A S$ expression of EOC and matched normal tissues examined. 
an exonic variant in $H O X A 11-A S(\mathrm{~A}>\mathrm{T}$; $\mathrm{MAF}=0.20)$ as being marginally associated with a decreased risk for serous $\mathrm{EOC}(\mathrm{OR}=0.88, P=0.06)$. Regardless of genotype, the HOXA11-AS is a tumor-suppressive lncRNA involved in EOC cell survival and proliferation. A series of functional assays provided compelling evidence for an allele-specific effect on tumor growth and several intermediate oncogenic phenotypes: migration, invasion, mitotic index, and apoptosis.

Previous studies have shown that distal $H O X A$ protein-coding genes are important in normal ovarian development and that changes in expression occur in ovarian tumors of epithelial origin $[2,4]$, but the functional role and expression of $\operatorname{lncRNAs}$ residing within this region are largely unknown. Through experimental investigation we have shown that ectopic expression of HOXA11-AS rs17427875 common and minor allele results in tumor suppressive phenotypes in vitro. Notably, expression of minor allele exhibited more significant tumor suppressive activity than common allele. Mouse xenograft studies recapitulate in vivo the significant phenotypes associated with expression of the minor allele. These findings are consistent with the observation that rs17427875 was associated with a trend towards decreased risk for serous EOC in the epidemiologic study. Moreover, in 18 RNA normal-tumor pairs from EOC patients, we observed significant down-regulation of $H O X A 11-A S$ in serous EOC tumors versus normal ovarian tissue. This observation further reinforces our experimental data that $H O X A 11-A S$ functions as a tumor suppressor.

Antisense lncRNAs can be involved in regulating of the expression of their neighboring genes in cis or more distant genes via a trans mechanism [22]. Accumulating studies show that a number of antisense lncRNAs demonstrate cis regulation of their neighboring genes. For instance, $A N R I L$ (antisense non-coding RNA in the INK4 locus) was shown to silence the INK4b-ARF-INK4A locus by recruiting the PRC1 and PRC2 complex [24]. ANRASSF1 (antisense intronic non-coding RASSF1) recruits $\mathrm{PRC} 2$ to the $R A S S F 1 A$ promoter, which leads to the accumulation of the repressive mark H3K27me3 and reduction in the RASSF1A transcription [25]. However, our data show that knockdown or overexpression of HOXA11-AS does not affect expression of its neighboring genes HOXA11 and HOXA13 (Figure 6). Since some lncRNAs have been shown to function as miRNA sponges, we queried the RNA22 database with HOXA11$A S$ sequence and did not find miRNA binding sites within the rs17427875 region (data not shown). In addition, the RNAsnp database analysis shows that minor allele does not cause secondary structure change of HOXA11$A S$ when compared to the common allele (Supplemental Figure 3). These findings suggest that $H O X A 11-A S$ exerts its cellular function possibly through trans regulation of
$\mathbf{A}$
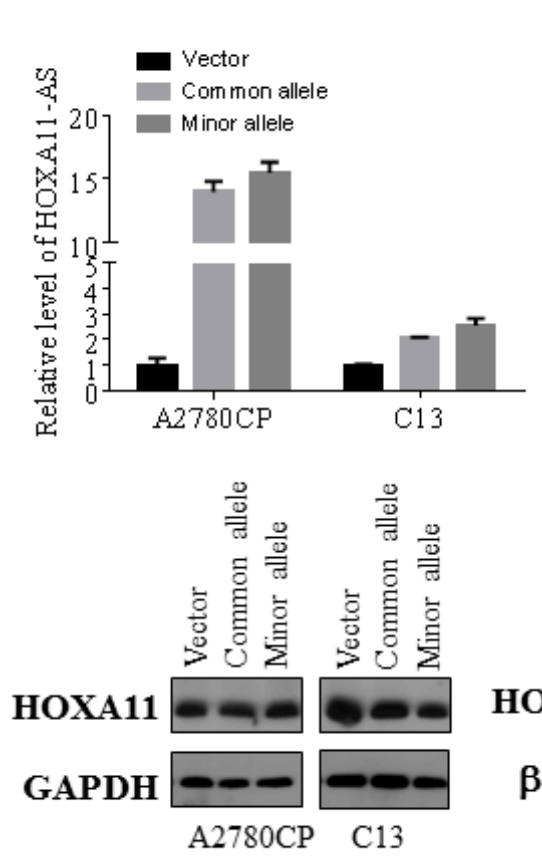

B

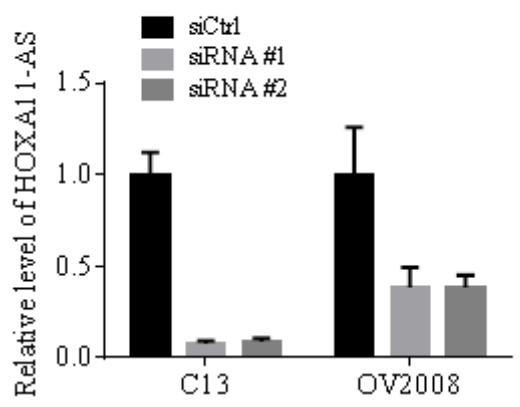

C

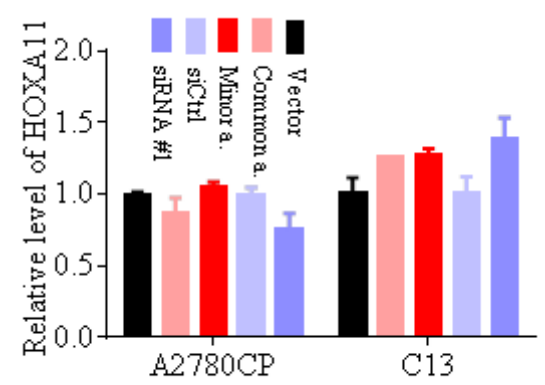

D

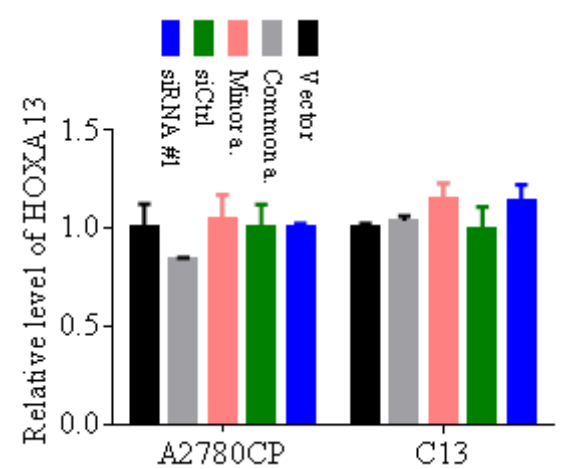

Figure 6: HOXA11- $A S$ has no effects on HOXA11 and HOXA13 expression. A. and B. Indicated cell lines were transfected with common, minor allele and siRNAs of HOXA11-AS as well as vector and control siRNA. Following incubation for 48 hours, the cells were subjected to RT-qPCR analysis (upper panels) and western blot with antibodies against HOAX11, GAPDH and $\beta$-actin (bottom panels). C. and D. Indicated cell lines were treated as panels A and B and then were analyzed for HOXA11 and HOXA13 mRNA levels by RT-qPCR. 
distant genes.

With the rapid growth of identified lncRNAs and disease-associated SNPs, there is a great interest in studying SNPs in lncRNAs [26]. For instance, the rs2839698 TC genotype of lncRNA H19 was associated with a reduced risk of developing non-muscle-invasive bladder cancer [27]. The SNP rs6983267 within lncRNA CCAT2 has been implicated in predisposition to colorectal and prostate cancer [28]. A recent study has shown that this SNP affects the expression of CCAT2, thereby impacting tumor growth and metastasis in colorectal cancer [29]. Moreover, SNP rs920778, which locates in intron 2 of lncRNA HOTAIR, has recently been shown to be associated with esophageal squamous cell carcinoma risk and regulation of HOTAIR expression [30]. However, although $H O X A 11-A S$ was down-regulated in EOC (Figure 5), rs17427875 had no effect on HOXA11-AS expression (Supplemental Figure 2). This could potentially be attributed to the small number of evaluated samples, or may indicate a different mechanism of action. It is important to note that while we were performing our in vitro and in vivo experiments, a larger dataset from the COGS genotyping initiative [31] became available. The association we observed with rs17427875 (A > T) in HOXA11- $A S$ was not replicated among an independent set of cases with serous histology $(\mathrm{OR}(95 \% \mathrm{CI})=1.00(0.95$ $1.06), p=0.98)$, and no associations were suggested for other lncRNA SNPs in the region. The basis for lack of consistency in the epidemiologic data is not immediately apparent but may be due to heterogeneity between study populations included in our North American GWAS and those included in COGS, an international genotyping initiative. It is also possible that the initial association observed in the North American GWAS was a falsepositive finding. This is a challenge inherent in the detection of weak effects with EOC as an endpoint. Nonetheless, the functional impact of the rs17427875 T minor allele was strong for several oncogenic phenotypes and our data demonstrate that non risk-associated polymorphisms can have allele-specific functionality, which is an important consideration for investigators performing post-GWAS functional studies. Regardless of genotype, this study provides strong evidence for the role of $H O X A 11-A S$ in EOC.

\section{MATERIALS AND METHODS}

\section{Study design and population}

Details of the study design and population have been previously described [32]. Briefly, we conducted a GWAS of North American EOC case-control studies. Characteristics of the participating studies are summarized in Table 1. Cases were women diagnosed with pathologically-confirmed primary invasive EOC fallopian tube cancer, or primary peritoneal cancer ascertained from clinic-, population-, and hospital-based studies and cancer registries. To increase homogeneity, our primary analysis focused on serous adenocarcinomas, the most common histologic subtype of EOCs [33]. Moreover, most of the cases had high-grade disease. The vast majority of the cases do not have a family history of ovarian or breast cancer in a first-degree relative, and most have not been tested for BRCA1 or BRCA2 mutations. Controls were women without a current or prior history of EOC with at least one ovary intact at the reference date. All studies had data on disease status, age at diagnosis/interview, selfreported racial group, and histologic subtype. Most studies frequency-matched cases and controls on age group and race. For the present analysis, we focused on subjects of European ancestry since they represent the vast majority of subjects and the burden of EOC is the highest in this racial group [33]. European ancestry was confirmed using principal component analysis [34] with HapMap CEU populations.

\section{Informed consent}

All participants provided written informed consent for their samples and data to be used. The protocol was approved by the institutional review board at each study site.

\section{Genotyping, quality control, and imputation}

Genotypes were generated using different versions of the Illumina Infinium arrays (Table 1). Genotyping methods and sample and SNP quality control procedures have been described previously [35]. Briefly, samples were excluded if they had a call rate $<95 \%,>1 \%$ discordance, $<80 \%$ European ancestry, or ambiguous gender. SNPs were excluded if they had call rates $<95 \%$ or if they had minor allele frequencies (MAF) less than 5\%. To account for different marker sets and improve genome coverage, genotype data was imputed for GWAS participants based on data from all 14 populations in the 1000 genomes project (1KGP, version 3, March 2012 release)) as the reference using IMPUTE2 version 2 after pre-phasing with SHAPEIT [36-38]. Before imputation, we excluded poor performing SNPs according to the genotyping success rates, deviation from Hardy Weinberg Equilibrium (HWE) with $P<1.0 \times 10^{-5}$, replicate errors, and rare MAF. To ensure the quality of imputed genotypes, maximum likelihood genotype imputation was carried out and an estimate of the squared correlation between imputed and true genotypes was calculated. Imputed SNPs with an R-square $<0.25$ were excluded. 


\section{Identification of variants in candidate HOXA IncRNA cluster genes}

The coordinates for each of 3 candidate human HOXA lncRNA genes (HOXA10-AS, HOXA11-AS, and HOTTIP) were used to identify SNPs falling within the designated gene sequences. To annotate the coordinates for these lncRNAs, we used GENCODEdb (http://www. gencodegenes.org/), the most comprehensive lncRNA annotation available [39]. A total of 72 variants in these 3 genes were represented in the imputed GWAS dataset. After filtering out the variants whose distribution deviated from HWE or had a MAF $<5 \%$, a total of 21 non-coding SNPs falling within the 3 HOXA lncRNA genes remained.

\section{Association testing}

We performed SNP-level association tests for the 21 identified SNPs using the pooled GWAS dataset. For each variant, unconditional logistic regression treating alternate alleles as an ordinal variable (a log-additive model) was used to evaluate individual SNP-serous EOC risk associations. Models were adjusted for study site and the first principal component (PC) representing European ancestry. To adjust for multiple comparisons, we estimated the false discovery rate (FDR) and used a corresponding q-value [40] of $10 \%$ to declare statistical significance. Statistical analyses were carried out using SAS (Version 9.3; SAS Inc.), PLINK (Version 1.07) [41], Matlab (R2011b; the Mathwork Inc.), and R (Version 3.0.2).

\section{Quantitative and semi-quantitative RT-PCR}

Total RNA was isolated using Trizol reagent following manufacturer's protocol and was used to generate cDNA with High Capacity cDNA Reverse Transcription Kit (Life Technologies, Carlsbad, CA, USA). Quantitative (real-time) PCR was performed with SYBR Green 2x Master Mix (Life Technologies Carlsbad, CA, USA) on ABI HT9600 from Applied Biosystems (Foster City, CA, USA). Cycle threshold (CT) values were generated and analyzed using ABI SDS version 2.3. Delta CTs were normalized to GAPDH reference gene, and $\Delta \Delta \mathrm{CT}$ analysis was performed to calculate relative expression of RNA. Patient RNA was extracted from archived human primary EOC tissue and matched adjacent "normal" ovarian surface epithelial cells from each of 18 patients from the Moffitt Cancer Center Total Cancer Care Biorepository [42]. Briefly, 500 ng samples of total RNA were used for RT reaction, and $2 \mathrm{ul}$ of the RT product was used for subsequent semi-qPCR reaction. Quantification of PCR was performed using ImageJ software and plotted as a ratio of HOXA11-AS/GAPDH. Real-time PCR primers for HOXA11-AS and GAPDH are listed in Supplementary
Table 1. After quantifying mRNA expression levels, we compared the expression levels between matched pairs of samples using the Wilcoxon sign rank test.

HOXA11-AS common and minor allele expression plasmids Full-length insert of the common allele of HOXA11-AS was amplified using reverse transcription (RT) product as template and cloned to pcDNA3.1 vector (Life Technologies, Carlsbad, CA USA) at EcoRI/XbaI sites. After common allele expression construct was confirmed by sequencing, the minor allele expression plasmid was generated using QuikChange ${ }^{\circledR}$ Site-Directed Mutagenesis Kit (Agilent Technologies, Santa Clara, CA USA) and introducing SNP as point mutation in insert. The primers used for HOXA11-AS site directed mutagenesis are listed in Supplementary Table 1.

\section{Proliferation and survival assays}

OVCA-433 and C13 cell lines were generous gifts from Xianghong Wang (University of Hong Kong) and Benjamin Tsang (Ottawa Hospital and Research Institute), respectively. Both cell lines were cultured under normal conditions using RPMI-1640 supplemented with $10 \%$ fetal bovine serum. OVCA-433 and C13 cells were seeded into chamber slides and transfected with vector, common, and minor allele constructs and cultured under G418 selection. EdU nucleoside analogue was allowed to incorporate during DNA synthesis for 1 hour. Cells were processed using Click-iT EdU Imaging Kit (Life Technologies) according to manufacturer's protocol. Relative proliferation was quantified by taking mean and standard deviations of 4 non-biased image fields. To assess overall cell survival, $4 \times 10^{4}$ cells per well were seeded in 12-well plates and transfected with constructs using 4 replicates. After 6 days selection, overall survival was assayed using $0.5 \mathrm{mg} / \mathrm{ml}$ MTT reagent (Sigma, St.Louis, MO USA), solubilized in DMSO, and read at $590 \mathrm{~nm}$.

\section{Migration and invasion assays}

EOC cells were transfected for 48 hours with vector, common allele, or minor allele $H O X A 11-A S$ constructs. Cells were washed, trypsinized, and seeded into the upper chamber of Boyden Chambers coated with (invasion) and without (migration) Matrigel. All top chambers contained serum free media while lower chambers had RPMI media containing $10 \%$ fetal bovine serum. After 16 hours, top chambers were cleared with cotton swab, washed in PBS, and bottom chamber was stained in crystal violet containing 10\% methanol. Migration and invasion were quantified by taking mean and standard deviations of 4 non-biased image fields. 


\section{Mouse xenograft model}

Animal studies were approved by the Institutional Animal Care and Use Committee at University of South Florida. Six weeks old female $\mathrm{Nu} / \mathrm{Nu}$ mice were purchased from Charles River Laboratories (Wilmington, MA USA). $\mathrm{C} 13$ cells were transfected with vector, common allele, or minor allele constructs and stably selected with G418 for 2 weeks. Cells were washed in PBS, trypsinized, and resuspended in PBS. Eight mice from each group received $4 \times 10^{6}$ cells/100ul injection subcutaneously. Tumor volume was measured via standard caliper measurements and tumor weight was calculated at endpoint. Tumor sections were histologically analyzed and were examined with Tunel assay.

\section{Western blot analysis of $H O X A 11-A S$ effect on its neighboring gene expression}

In addition C13, A2780CP and OV2008 cells, which were gifts from Benjamin Tsang (Ottawa Hospital and Research Institute), were transfected with the common and minor allele plasmids and 2 siRNAs of HOXA11-AS. Following incubation for 48 hours, the cells were subjected to western blot analysis with antibody against HOXA11. The siRNA sequences are listed in Supplementary Table 1.

\section{ACKNOWLEDGMENTS}

We thank all of the women who participated in this research along with all of the researchers, clinicians, and staff who have contributed to the participating studies.

\section{CONFLICTS OF INTEREST}

The authors declare no conflicts of interest.

\section{GRANT SUPPORT}

This study was supported by funding from the Genetic Associations and Mechanisms in Oncology (GAME-ON): a NCI Cancer Post-GWAS Initiative (U19CA148112). This study was also supported by NIH/NCI (R01-CA160455 and R01-CA137041) and the Ovarian Cancer Research Fund thanks to donations by the family and friends of Kathryn Sladek Smith (PPD/RPCI.07). The genotyping, bioinformatics, and biostatistical analysis for MAY, NCO, TBO, and TOR were supported by R01CA114343 and R01-CA114343-S1. The MAY study is also supported by R01-CA122443, P50-CA136393, P30-CA15083 and funding from the Mayo Foundation, the Minnesota Ovarian Cancer Alliance, and the Fred B. and Katherine B. Andersen Foundation. The Mayo Clinic Genotyping Shared Resource was supported by the National Cancer Institute (P30-CA15083). The NCO study is supported by R01-CA76016 and DAMD17-02-10666. The TBO study is supported by R01-CA106414, the American Cancer Society (CRTG-00-196-01-CCE), the Advanced Cancer Detection Center Grant, Department of Defense (DAMD-17-98-1-8659), and the Celma Mastery Ovarian Cancer Foundation. The TOR study is supported by grants from the Canadian Cancer Society and the NIH (R01-CA63682 and R01-CA63678). The NEC study is supported by grants R01-CA54419 and P50-CA105009. Moffitt Cancer Center Biostatistics and Cancer Informatics Cores were supported in part by grant P30-CA76292.

\section{Author Contributions}

T.A.S., J.Q.C. E.J.R. and J. P-W. designed research; E.J.R., J. P-W., Y.L., Y.A.C., D.C., B.M.R., H-Y.L., and J.K.T. performed research; A.B., M.J.B., K.L., A.N.A.M., J.M.S., E.L.G. and S.A.G. provided patient database and advised the manuscript; J. P-W., E.J.R., T.A.S. and J.Q.C. wrote the manuscript.

\section{REFERENCES}

1. Bhatlekar S, Fields JZ and Boman BM. HOX genes and their role in the development of human cancers. J Mol Med (Berl). 2014; 92:811-823.

2. Kelly ZL, Michael A, Butler-Manuel S, Pandha HS and Morgan RG. HOX genes in ovarian cancer. J Ovarian Res. $2011 ; 4: 16$.

3. Garcia-Fernandez J. The genesis and evolution of homeobox gene clusters. Nat Rev Genet. 2005; 6:881-892.

4. Cheng W, Liu J, Yoshida H, Rosen D and Naora H. Lineage infidelity of epithelial ovarian cancers is controlled by HOX genes that specify regional identity in the reproductive tract. Nat Med. 2005; 11:531-537.

5. Ferlay J, Shin HR, Bray F, Forman D, Mathers C and Parkin DM. Estimates of worldwide burden of cancer in 2008: GLOBOCAN 2008. Int J Cancer. 2010; 127:2893-2917.

6. Naora H, Montz FJ, Chai CY and Roden RB. Aberrant expression of homeobox gene HOXA7 is associated with mullerian-like differentiation of epithelial ovarian tumors and the generation of a specific autologous antibody response. Proc Natl Acad Sci U S A. 2001; 98:1520915214 .

7. Ota T, Gilks CB, Longacre T, Leung PC and Auersperg N. HOXA7 in epithelial ovarian cancer: interrelationships between differentiation and clinical features. Reprod Sci. 2007; 14:605-614.

8. Ota T, Klausen C, Salamanca MC, Woo HL, Leung PC and Auersperg N. Expression and function of HOXA genes in normal and neoplastic ovarian epithelial cells. Differentiation. 2009; 77:162-171.

9. Yamashita T, Tazawa S, Yawei Z, Katayama H, Kato Y, 
Nishiwaki K, Yokohama Y and Ishikawa M. Suppression of invasive characteristics by antisense introduction of overexpressed HOX genes in ovarian cancer cells. Int $\mathbf{J}$ Oncol. 2006; 28:931-938.

10. Qiu JJ, Lin YY, Ye LC, Ding JX, Feng WW, Jin HY, Zhang Y, Li Q and Hua KQ. Overexpression of long noncoding RNA HOTAIR predicts poor patient prognosis and promotes tumor metastasis in epithelial ovarian cancer. Gynecol Oncol. 2014; 134:121-128.

11. Bertani S, Sauer S, Bolotin E and Sauer F. The noncoding RNA Mistral activates Hoxa6 and Hoxa7 expression and stem cell differentiation by recruiting MLL1 to chromatin. Mol Cell. 2011; 43:1040-1046.

12. Richards EJ, Zhang G, Li ZP, Permuth-Wey J, Challa S, Li Y, Kong W, Dan S, Bui MM, Coppola D, Mao WM, Sellers TA and Cheng JQ. Long non-coding RNAs (LncRNA) regulated by transforming growth factor (TGF) beta: LncRNA-hit-mediated TGFbeta-induced epithelial to mesenchymal transition in mammary epithelia. J Biol Chem. 2015; 290:6857-6867.

13. Wang KC, Yang YW, Liu B, Sanyal A, Corces-Zimmerman R, Chen Y, Lajoie BR, Protacio A, Flynn RA, Gupta RA, Wysocka J, Lei M, Dekker J, Helms JA and Chang HY. A long noncoding RNA maintains active chromatin to coordinate homeotic gene expression. Nature. 2011; 472:120-124.

14. Cheetham SW, Gruhl F, Mattick JS and Dinger ME. Long noncoding RNAs and the genetics of cancer. Br J Cancer. 2013; 108:2419-2425.

15. Chung S, Nakagawa H, Uemura M, Piao L, Ashikawa K, Hosono N, Takata R, Akamatsu S, Kawaguchi T, Morizono T, Tsunoda T, Daigo Y, Matsuda K, Kamatani N, Nakamura $\mathrm{Y}$ and Kubo M. Association of a novel long non-coding RNA in 8q24 with prostate cancer susceptibility. Cancer Sci. 2011; 102:245-252.

16. Jin G, Sun J, Isaacs SD, Wiley KE, Kim ST, Chu LW, Zhang Z, Zhao H, Zheng SL, Isaacs WB and Xu J. Human polymorphisms at long non-coding RNAs (lncRNAs) and association with prostate cancer risk. Carcinogenesis. 2011; 32:1655-1659.

17. Liu Y, Pan S, Liu L, Zhai X, Liu J, Wen J, Zhang Y, Chen J, Shen $\mathrm{H}$ and $\mathrm{Hu} \mathrm{Z}$. A genetic variant in long noncoding RNA HULC contributes to risk of HBV-related hepatocellular carcinoma in a Chinese population. PLoS One. 2012; 7:e35145.

18. Jendrzejewski J, He H, Radomska HS, Li W, Tomsic J, Liyanarachchi S, Davuluri RV, Nagy R and de la Chapelle A. The polymorphism rs 944289 predisposes to papillary thyroid carcinoma through a large intergenic noncoding RNA gene of tumor suppressor type. Proc Natl Acad Sci U S A. 2012; 109:8646-8651.

19. Pasmant E, Sabbagh A, Vidaud M and Bieche I. ANRIL, a long, noncoding RNA, is an unexpected major hotspot in GWAS. FASEB J. 2011; 25:444-448.
20. Potter SS and Branford WW. Evolutionary conservation and tissue-specific processing of Hoxa 11 antisense transcripts. Mamm Genome. 1998; 9:799-806.

21. Lengyel E. Ovarian cancer development and metastasis. Am J Pathol. 2010; 177:1053-1064.

22. Villegas VE and Zaphiropoulos PG. Neighboring gene regulation by antisense long non-coding RNAs. Int J Mol Sci. 2015; 16:3251-66.

23. Grier DG, Thompson A, Kwasniewska A, McGonigle GJ, Halliday HL and Lappin TR. The pathophysiology of HOX genes and their role in cancer. J Pathol. 2005; 205:154-171.

24. Yap KL, Li S, Muñoz-Cabello AM, Raguz S, Zeng L, Mujtaba S, Gil J, Walsh MJ, Zhou MM. Molecular interplay of the noncoding RNA ANRIL and methylated histone H3 lysine 27 by polycomb CBX7 in transcriptional silencing of INK4a. Mol Cell. 2010; 38:662-74.

25. Beckedorff FC, Ayupe AC, Crocci-Souza R, Amaral MS, Nakaya HI, Soltys DT, Menck CF, Reis EM and VerjovskiAlmeida S. The intronic long noncoding RNA ANRASSF1 recruits PRC2 to the RASSF1A promoter, reducing the expression of RASSF1A and increasing cell proliferation. PLoS Genet. 2013; 9:e1003705

26. Gong J, Liu W, Zhang J, Miao $\mathrm{X}$ and Guo AY. lncRNASNP: a database of SNPs in lncRNAs and their potential functions in human and mouse. Nucleic Acids Res. 2015; 43:D181-186.

27. Verhaegh GW, Verkleij L, Vermeulen SH, den Heijer M, Witjes JA and Kiemeney LA. Polymorphisms in the H19 gene and the risk of bladder cancer. Eur Urol. 2008; 54:1118-1126.

28. Haiman CA, Le Marchand L, Yamamato J, Stram DO, Sheng X, Kolonel LN, Wu AH, Reich D and Henderson BE. A common genetic risk factor for colorectal and prostate cancer. Nat Genet. 2007; 39:954-956.

29. Ling H, Spizzo R, Atlasi Y, Nicoloso M, Shimizu M, Redis RS, Nishida N, Gafa R, Song J, Guo Z, Ivan C, Barbarotto E, De Vries I, Zhang X, Ferracin M, Churchman $\mathrm{M}$, et al. CCAT2, a novel noncoding RNA mapping to $8 \mathrm{q} 24$, underlies metastatic progression and chromosomal instability in colon cancer. Genome Res. 2013.

30. Zhang X, Zhou L, Fu G, Sun F, Shi J, Wei J, Lu C, Zhou C, Yuan Q and Yang M. The identification of an ESCC susceptibility SNP rs920778 that regulates the expression of lncRNA HOTAIR via a novel intronic enhancer. Carcinogenesis. 2014; 35:2062-2067.

31. Permuth-Wey J, Lawrenson K, Shen HC, Velkova A, Tyrer JP, Chen Z, Lin HY, Ann Chen Y, Tsai YY, Qu X, Ramus SJ, Karevan R, Lee J, Lee N, Larson MC, Aben $\mathrm{KK}$, et al. Identification and molecular characterization of a new ovarian cancer susceptibility locus at $17 \mathrm{q} 21.31$. Nat Commun. 2013; 4:1627.

32. Permuth-Wey J, Chen Z, Tsai YY, Lin HY, Chen YA, Barnholtz-Sloan J, Birrer MJ, Chanock SJ, Cramer DW, Cunningham JM, Fenstermacher D, Fridley BL, Garcia- 
Closas M, Gayther SA, Gentry-Maharaj A, GonzalezBosquet J, et al. MicroRNA processing and binding site polymorphisms are not replicated in the Ovarian Cancer Association Consortium. Cancer Epidemiol Biomarkers Prev. 2011; 20:1793-1797.

33. Permuth-Wey J and Sellers TA. Epidemiology of ovarian cancer. Methods Mol Biol. 2009; 472:413-437.

34. Price AL, Patterson NJ, Plenge RM, Weinblatt ME, Shadick NA and Reich D. Principal components analysis corrects for stratification in genome-wide association studies. Nat Genet. 2006; 38:904-909.

35. Permuth-Wey J, Kim D, Tsai YY, Lin HY, Chen YA, Barnholtz-Sloan J, Birrer MJ, Bloom G, Chanock SJ, Chen Z, Cramer DW, Cunningham JM, Dagne G, EbbertSyfrett J, Fenstermacher D, Fridley BL, et al. LIN28B polymorphisms influence susceptibility to epithelial ovarian cancer. Cancer Res. 2011.

36. Howie BN, Donnelly P and Marchini J. A flexible and accurate genotype imputation method for the next generation of genome-wide association studies. PLoS Genet. 2009; 5:e1000529.

37. Delaneau O, Zagury JF and Marchini J. Improved wholechromosome phasing for disease and population genetic studies. Nat Methods. 2013; 10:5-6.

38. Howie B, Fuchsberger C, Stephens M, Marchini J and Abecasis GR. Fast and accurate genotype imputation in genome-wide association studies through pre-phasing. Nat Genet. 2012; 44:955-959.

39. Derrien T, Johnson R, Bussotti G, Tanzer A, Djebali S, Tilgner H, Guernec G, Martin D, Merkel A, Knowles DG, Lagarde J, Veeravalli L, Ruan X, Ruan Y, Lassmann T, Carninci $\mathrm{P}$, et al. The GENCODE v7 catalog of human long noncoding RNAs: analysis of their gene structure, evolution, and expression. Genome Res. 2012; 22:17751789.

40. Storey JD and Tibshirani R. Statistical significance for genomewide studies. Proc Natl Acad Sci U S A. 2003; 100:9440-9445.

41. Purcell S, Neale B, Todd-Brown K, Thomas L, Ferreira MAR, Bender D, Maller J, Sklar P, de Bakker PIW, Daly MJ and Sham PC. PLINK: A Tool Set for Whole-Genome Association and Population-Based Linkage Analyses. The American Journal of Human Genetics. 2007; 81:559-575.

42. Fenstermacher DA, Wenham RM, Rollison DE and Dalton WS. Implementing personalized medicine in a cancer center. Cancer J. 2011; 17:528-536. 